\title{
UNA APROXIMACIÓN A LAS SABIDURÍAS ORIENTALES NO DUALES
}

\section{AN APPROACH TO THE NON-DUAL EASTERN WISDOM}

\author{
María Teresa ROMÁN LÓPEZ* \\ Departamento de Filosofía. UNED
}

\begin{abstract}
RESUMEN: La idea de la no-dualidad entre sujeto y objeto, entre conocedor y conocido, fundamental en el vedânta advaita, en ciertas corrientes taoístas y en las escuelas mâdhyamaka y yogâchâra del budismo mahâyâna (las grandes estructuras filosóficas del mundo oriental) y tan alejada de la estructura cognitivo-emocional operativa implantada en Occidente, constituye el objeto de estudio del presente artículo.

PALABRAS CLAVE: «Filosofía perenne», mâyâ, no-dualidad, vedânta advaita, escuelas taoístas, escuelas mâdhyamaka y yogâchâra del budismo mahâyâna.

ABSTRACT: The non-duality idea between subject and object, and between knower and known, essential in the Vedânta Advaita, in certain Taoist currents, in the Mâdhyamaka, and in the Yogâchâra schools of the Mahâyâna Buddhism (the philosophical leading structures of the Eastern world); an idea so far from the cognitive-emotional setting that prevails in the West is the object of study of the present article.
\end{abstract}

* Este trabajo se inserta en el Proyecto de Investigación «I+D+i» no FFI20008-00725, concedido por el Ministerio de Ciencia e Innovación y cuyo título es: «Crítica de la religión, imágenes de la alteridad y cosmopolitismo. Una nueva visión del pensamiento ilustrado y una defensa de su vigencia». 
KEYwORDS: «Perennial philosophy», Mâyâ, non-duality, Vedânta Advaita, Taoist schools, Mâdhyamaka and Yogâchâra schools of the Buddhism Mahâyâna.

Una filosofía abierta no excluye ninguna forma de aproximación a la verdad.

R. Panikkar

\section{Introducción}

El espacio de que disponemos no nos permite examinar en su totalidad la riqueza de matices de las Sabidurías orientales no duales, ni siquiera el terreno sobre el que se sustenta, a saber: la no-dualidad. Sin embargo, nada nos impide acercar el tema, como si utilizáramos una lupa de gran aumento, y poner al descubierto una parte minúscula del núcleo básico de sus contenidos.

Los más importantes "productos filosóficos» expuestos y desarrollados por los filósofos griegos antiguos y que han definido los itinerarios básicos de la filosofía (sobre todo de la occidental) así como el objeto de sus diversas disciplinas, son dualidades. El conocimiento dualista según el cual el universo se manifiesta en dos grandes apartados: observador y observado, conocedor y conocido, sujeto y objeto, es el motor de la filosofía, de la teología y de la ciencia occidentales. «La filosofía occidental, en general, es la griega y la filosofía griega es la filosofía de los dualismos. La mayoría de los principales temas filosóficos debatidos todavía hoy fueron creados y modelados por los filósofos de la antigua Grecia. Entre ellos se encuentra el dualismo de la verdad frente a la mentira, cuyo estudio recibe el nombre de «lógica»; el de la bondad frente a la maldad, denominado «ética»; y el de la apariencia frente a la realidad, llamado «epistemología». Los griegos iniciaron también el estudio a gran escala de la "ontología», o exploración de la naturaleza esencial o ser del universo, basando sus primeras investigaciones en los dualismos de uno frente a muchos, el caos frente al orden, y la simplicidad frente a la complejidad» ${ }^{1}$.

${ }^{1}$ K. Wilber, El espectro de la conciencia, Kairós, Barcelona, 1990, pp. 36-37. 
Sin embargo, en las fecundas tierras intelectuales de China e India prosperaron las vigorosas semillas que plantaron grandes sabios-filósofos (Zhuang zi, Nâgârjuna, Shankara, etc.); una de estas simientes, la de la no-dualidad entre el observador y lo observado, la eliminación de la construcción mental sujeto-objeto por la que se ha deslizado la filosofía y la ciencia occidentales, no sólo prendió, sino que se desarrolló de tal forma que dio lugar a una importante variedad de grupos y movimientos de gran envergadura filosófica: diversas corrientes del taoísmo filosófico, el vedânta advaita hindú ${ }^{2}$ y las escuelas mâdhyamaka, shûnyavâda o escuela de la vacuidad y yogâchâra, chitamattra o escuela de "sólo la Mente» del budismo mahâyâna; ninguna de ellas tiene reparos en afirmar la existencia de una forma no dual de experimentar y de relacionarse con el mundo ${ }^{3} y$ advierten que las tendencias dicotomizadoras de la mente son las que no nos permiten percibir las situaciones sin asignarles categorías dualistas: «La mayoría de las personas civilizadas han perdido el contacto con la realidad. Confunden el mundo tal como es con el mundo tal como ellos lo piensan, tal como hablan de él y lo describen. Porque por una parte está el mundo real y por otra hay todo un sistema de símbolos — referentes a ese mundo-que llevamos en nuestra mente. Son símbolos muy, muy útiles; toda la civilización depende de ellos [...] y la principal desventaja de los símbolos es que los confundimos con la realidad, de la misma manera que confundimos el dinero con la auténtica riqueza y nuestro nombre, la idea y la imagen que tenemos de nosotros mismos, con nosotros» ${ }^{4}$.

El principal mensaje de las Upanishads 5 , el cenit del antiguo pensamiento de la India, es la identidad del espíritu individual (âtman) con el espíritu universal

2 «El Vedânta Advaita es el sistema no dualista del Vedânta expuesto originariamente por Shankara (788-820 d. JC.). Ha sido y sigue siendo el sistema de pensamiento de mayor aceptación entre los filósofos indios y creemos que es uno de los productos filosóficos más grandes que pueden hallarse en Oriente y Occidente». E. Deutsch, Vedânta Advaita. Una reconstrucción filosófica, Etnos, Madrid, 1999, p. 11.

3 «Ninguno de esos tres sistemas rechaza de plano el mundo dualista «relativo» con que el tan familiarizados nos hallamos y que terminamos confundiendo con el «sentido común», el mundo en tanto colección de objetos discretos que interactúan causalmente en el espacio y en el tiempo. Lo que estos sistemas afirman, por el contrario, es la existencia de una forma no-dual de experimentar el mundo, una modalidad más real y elevada que la modalidad dualista que los occidentales damos por sentada». D. Loy, No dualidad, Kairós, Barcelona, 2000, p. 17.

${ }^{4}$ A. Watts, Nueve meditaciones, Kairós, Barcelona, 1981, p. 29.

5 Conocidas como los «Himalayas del alma», las Upanishads son el punto culminante del antiguo pensamiento de la India; las más antiguas fueron compuestas aproximadamente entre los años 
(Brahman). En la Chândogya Upanishad, el sabio Uddâlaka Âruni dice a Shvetaketu: «Hijo mío, en el principio este mundo era, en verdad, únicamente ser, uno y sin segundo" ${ }^{6}$. La Bhagavad gîtâ, una de las grandes obras didáctico-filosóficas de la India, afirma: «Considerando por igual el placer y el dolor, la ganancia y la pérdida, el triunfo y la derrota ${ }^{7}$. Uno de los grandes representantes contemporáneos de la tradición advaita, Ramana Maharshi, señala: «La vigilia es larga y un sueño es corto; aparte de eso, no hay diferencia. Así como los acontecimientos de la vigilia parecen reales mientras estamos despiertos, lo mismo sucede con los de un sueño mientras soñamos. Al soñar, la mente asume otro cuerpo. Tanto en los estados de vigilia como en los sueños se dan simultáneamente pensamientos, nombres y formas» ${ }^{8}$. Por su parte, en un texto del budismo mahâyâna leemos: «No te entretengas con el dualismo, evita cuidadosamente perseguirlo; tan pronto tengas lo correcto y lo erróneo, lo que sigue es confusión, la mente se pierde» ${ }^{9}$. Y Nâgârjuna ${ }^{10}$, el máximo exponente de la escuela mâdhyamaka del budismo mahâyâna, afirma: "No hay diferencia alguna entre samsâra y nirvana, ni la hay entre nirvana y samsâra. La cima del nirvana es la cima del samsâra. Entre ambos, no es concebible ni la más sutil diferencia» ${ }^{11}$. Por su parte,

800 a 550 a.C., en prosa, en un lenguaje algo arcaico y son: Aitareya, Brihadâranyaka, Chândogya, Kaushîtaki, Kena y Taittirîya. Durante los siglos V al III a.C., fueron compuestas en sánscrito clásico y en verso las siguientes: Îshâ, Kâthaka, Shvetâshvatara, Mundaka y Mahânârâyana; y en prosa: Prashna, Maitrî y Mândûkya. Véase R.E. Hume (ed.), The thirteen principal Upanishads, Oxford University Press, Nueva Delhi, 1998; S. Radhakrishnan (ed.), The principal Upanisads, Allen \& Unwin, Londres, 1953; The philosophy of the Upanishads, Librairie d'Amérique et d'Orient, París, 1943; P. Deussen, The philosophy of the Upanishads, Dover Publications, Nueva York, 1966.

${ }^{6}$ Chândogya Upanishad 41,6.2,2. En la edición de F. Tola, Doctrinas secretas de la India Upanishads, Barral, Barcelona, 1973, p. 195.

7 Bhagavad gîtâ (II, 38). En la edición de F. Tola, Bhagavad-gîtâ. El canto del Señor, Monte Ávila Editores, Caracas, 1977, p. 47.

8 Ramana Maharshi, Enseñanzas espirituales, Kairós, Barcelona, 1986, p. 29.

9 D.T. Suzuki, Ensayos sobre budismo zen, Kier, Primera Serie, Buenos Aires, 1981, p. 216.

10 Autor de los «Fundamentos de la vía media» (Mûlamadhyamakakârikâh), una de las obras filosóficas más interesantes de la historia del pensamiento asiático, insistía en que el Buddha no defendía ninguna posición filosófica; sólo pretendía poner de manifiesto que todos los puntos de vista filosóficos son contradictorios e inadmisibles. En tanto que toda afirmación enunciada desde una perspectiva filosófica concreta no reconoce tácitamente las posiciones opuestas, parece que el grupo mâdhyamaka ha llevado la crítica del pensamiento dualista hasta sus últimas conclusiones filosóficas. Véase J. Arnau, La palabra frente al vació. Filosofía de Nâgârjuna, Fondo de Cultura Económica, México, 2005.

${ }^{11}$ Mûlamadhyamakakârikâh (XXV.19). Nâgârjuna, Fundamentos de la vía media. En la edición de J. Arnau, Siruela, Madrid, 2004, p. 191. 
Zhuang zi, uno de los más importantes representantes del taoísmo filosófico, declara: "¿Verdaderamente hay diferencia entre el otro y uno mismo?, ¿no hay realmente diferencia entre ambos? Que el otro y el yo no se contrapongan: a eso nombran eje del Tao. Sólo acomodándose a ese eje se puede penetrar en el círculo, para así corresponder a los infinitos cambios. Los cambios del «es» son infinitos, e infinitos los cambios del «no-es». Por eso se dice: nada mejor que una mente iluminada $»^{12}$. Finalmente, Thomas Merton afirma: «Hay otra conciencia metafísica al alcance del hombre moderno. No parte del sujeto pensante y autoperceptivo sino del Ser, ontológicamente considerado como anterior y englobante de la división sujeto-objeto. Por debajo de la experiencia subjetiva del yo individual hay una experiencia inmediata del Ser. Esta última es totalmente distinta de la experiencia consciente del yo. Resulta definidamente no-objetiva. Carece de la alienación y las lagunas características del sujeto que se percibe a sí mismo como un casi-objeto. La conciencia de Ser (al margen de que se la considere positivamente, o negativa y desapasionadamente como en el Budismo) es una experiencia inmediata que va más allá de la percepción reflexiva. No es «conciencia de» algo sino conciencia pura, en el seno de la cual «desaparece» el sujeto como tal» ${ }^{13}$.

Resulta muy lamentable que la doctrina de la no-dualidad haya pasado desapercibida para un amplio sector de la filosofía (tanto de oriente como de occidente). Es precisamente esa sorprendente declaración, a saber: la no-dualidad entre sujeto y objeto, entre conocedor y conocido, fundamental en el vedânta advaita, en ciertas corrientes taoístas y en las escuelas mâdhyamaka y yogâchâra del budismo mahâyâna (las grandes estructuras filosóficas del mundo oriental) y tan alejada de la estructura cognitivo-emocional operativa implantada en Occidente, la que ha avivado la llama de nuestra curiosidad.

\section{Sabidurías orientales no duales}

¿Cuál es la visión del mundo sustentada, de una u otra manera, por importantes sabios, filósofos, teólogos, e incluso científicos de diferentes épocas, luga-

\footnotetext{
12 Zhuang zi II, III. En la edición de I. Preciado, Zhuang zi «Maestro Chuang Tsé», Kairós, Barcelona, 1996, pp. 45-46.

13 T. Merton, El zen y los pájaros del deseo, Kairós, Barcelona, 1999, pp. 38-39.
} 
res y culturas? ¿Cuál es el núcleo esencial del consenso universal de las grandes tradiciones de sabiduría de nuestro planeta? ¿En qué consiste la visión del mundo que llevó a Aldous Huxley a escribir un libro con el título Philosophia Perennis («Filosofía Perenne») ${ }^{14}$ ? ¿Cuál es la visión del mundo que, como afirmaba Arthur Lovejoy es, «una de las principales concepciones del pensamiento occidental que ha llegado a conocerse con una denominación propia»? ${ }^{15}$.

Esta visión del mundo es conocida como Philosophia Perennis («Filosofía Perenne» ${ }^{16}$ ), «Tradición Unánime», «Sabiduría Primordial», «Sabiduría Antigua», «Sabiduría Perenne» ${ }^{17}$, «Religión Perenne» o «Psicología Perenne». Y es en el corazón de la "filosofía perenne» donde hallamos claramente expresada y desarrollada la doctrina de la no-dualidad: «La mente occidental ha dividido el mundo en dos mitades, el consciente y el inconsciente, el espíritu y la materia, el alma y el cuerpo, y la filosofía occidental oscila entre los dos extremos de materialismo e idealismo. Ello se debe a una enfermedad de la mente, a una esquizofrenia, que se ha desarrollado en el hombre occidental desde el Renacimiento, en que se pierde la visión unitiva

14 «Una visión — conocida con el nombre de «filosofía perenne» (el término fue acuñado por Leibniz) - que descansa en el núcleo esotérico del hinduismo, del budismo, del taoísmo, del sufismo y del misticismo cristiano; una visión, por último, que fue abrazada, parcial o totalmente, por individuos como Spinoza, Albert Einstein, Schopenhauer, Jung, William James y Platón. Además, en su forma más pura esta visión no es tanto una anticiencia como una transciencia - o, mejor dicho, una anteciencia-, lo cual la capacita para convivir — e incluso para complementar- los datos más duros que nos ofrecen las ciencias puras. Éste es el motivo, en mi opinión, por el cual muchos de los científicos más lúcidos — como Einstein, Schrödinger, Eddington, David Bohm, Sir James Jeans e incluso Isaac Newton — hayan coqueteado - y hasta hayan abrazado abiertamente— la filosofía perenne». K. Wilber, Después del edén, Kairós, Barcelona, 1995, p. 19.

15 A. O. Lovejoy, La Gran Cadena del Ser. Historia de una idea, Icaria, Barcelona, 1983, p. 29.

${ }^{16}$ La verdad olvidada: el factor común de todas las religiones de Huston Smith es la mejor introducción a esta visión del mundo conocida como «filosofía perenne».

17 «El término sabiduría "perenne», "primordial» o «antigua» tiene dos posibles significados. En primer lugar, puede referirse a la verdad sin forma radicalmente atemporal y aespacial, al fundamento del ser, al vacío primordial, al Espíritu puro sin manifestar [...]. Cuando nosotros descendemos de este plano atemporal de unión-samadhi sin forma y sin imágenes, revestimos naturalmente la realización de la verdad sin forma con los símbolos y formas de la verdad característicos de nuestro entorno sociocultural. Las formas y símbolos concretos externos utilizados por la sabiduría de las culturas pasadas han conducido al segundo gran significado del concepto de «sabiduría antigua», es decir, a las doctrinas, las palabras, las teorías, las metáforas, los símbolos y los modelos reales utilizados por las culturas antiguas o pasadas para expresar y encarnar su comprensión de la verdad esencial». K. Wilber, El ojo del espiritu, Una visión integral para un mundo que está enloqueciendo poco a poco, Kairós, Barcelona, 1998, pp. 77-78. 
de la Edad Media. La visión medieval es en otros aspectos inadecuada, y el hombre occidental tiene que recuperar su equilibrio volviendo a descubrir la visión del mundo antiguo, la filosofía perenne, que se encuentra plenamente desarrollada en el budismo vedanta y mahayana, pero que está implícita en toda religión antigua» ${ }^{18}$.

No existe afirmación filosófica más atractiva, más extraña y más ajena a los parámetros de la razón, al «sentido común», más incompatible con nuestra experiencia habitual, con nuestro estado de vigila, que la que señala la inexistencia de puentes entre el observador y lo observado, de filtros entre el ser humano y la Realidad ${ }^{19}$; en resumen, la no-dualidad ${ }^{20}$ o, lo que es lo mismo, estar más allá de los "estados ordinarios de conciencia» ${ }^{21}$, del mundo frag-

18 B. Griffiths, El matrimonio de Oriente y Occidente, Ediciones Paulinas, Madrid, 1985, p. 53.

19 Según Fromm, la educación social y los problemas individuales tienden a crear un filtro a través del cual sólo puede contemplarse un fragmento de la experiencia propia, para ser representada en la conciencia: «Durante el paso del inconsciente primitivo a la conciencia de sí, el mundo es experimentado como un mundo enajenado sobre la base de la separación entre sujeto y objeto, de la separación entre el hombre universal y el hombre social, entre el inconsciente y la conciencia. Sin embargo, en el grado en que la conciencia está adiestrada para abrirse, para suprimir el triple filtro, desaparece la discrepancia entre la conciencia y el inconsciente. Una vez que ha desaparecido plenamente hay una experiencia directa, no refleja, consciente, justo el tipo de experiencia que existe sin intelección ni reflexión». E. Fromm y D. T. Suzuki, Budismo zen y psicoanálisis, Fondo de Cultura Económica, Madrid, 1975, p. 143.

${ }^{20}$ En una nota de S. T. Coleridge leemos: «Si un hombre atravesara el Paraíso en un sueño, y le dieran una flor como prueba que había estado allí, y si al despertar encontrara esa flor en su mano... ¿entonces, qué?». J. L. Borges, Prosa completa, vol. 2, Bruguera, Barcelona, 1980, p. 138. Y en el Zhuang zi (II, VII) leemos: «Una noche Zhuang Zhou soñó que era una mariposa: una mariposa que revoloteaba, que iba de un lugar a otro contenta consigo misma, ignorante por completo de ser Zhou. Despertóse a deshora y vio, asombrado, que era Zhou. Más, ¿Zhou había soñado que era una mariposa? ¿O era una mariposa la que estaba ahora soñando que era Zhou?». Por último, E. Schrödinger declara: «Mundo exterior y conciencia son una y la misma cosa». Mi concepción del mundo, Tusquets, Barcelona, 1988, p. 54.

21 «La consciencia mental no es sino una gama y no agota todas las gamas de posibles consciencias [...] existen gamas de consciencia que se hallan por encima y por debajo de la gama humana, con las que el ser humano normal no está en contacto y que, por eso mismo, le parecen «inconscientes» gamas supramentales y gamas submentales... En realidad, eso que llamamos «inconsciencia» es, simplemente otra consciencia. No somos más «inconscientes» cuando estamos dormidos o sin sentido, cuando nos hallamos bajo el efecto de las drogas o estamos «muertos» o en cualquier otro estado, que cuando nos encontramos sumergidos en un pensamiento interior y nos hemos olvidado de nuestro yo físico y de todo cuanto nos rodea». Satprem, Sri Aurobindo o la aventura de la consciencia, Obelisco, Barcelona, 1983, pp. 65-66. Para William James: «Nuestra consciencia despierta, normal, la consciencia que llamamos racional, sólo es un tipo particular de consciencia, 
mentado ${ }^{22}$, «ilusorio» ${ }^{23}$, «semejante a un sueño ${ }^{24}$, consensuado ${ }^{25}$, «normal», convencional ${ }^{26}$, "políticamente correcto», jerárquico, dual, relativo, opues-

mientras que por encima de ella, separada por una pantalla transparente, existen formas potenciales de consciencia completamente diferentes [...] Ninguna explicación del universo en su totalidad puede ser definitiva si descuida estas otras formas de consciencia». Las variedades de la experiencia religiosa, Península, Barcelona, 1986, p. 291. Véase R. Guénon, Los estados múltiples del ser, Obelisco, Barcelona, 1987.

22 «Nuestro pensar es el resultado del conocimiento, y el conocimiento es siempre fragmentario. El conocimiento marcha siempre mano a mano con la ignorancia. No hay un conocimiento completo acerca de nada. Uno puede ser científico, ingeniero, psicólogo, etc., pero su pensar, que nace de su conocimiento, es siempre limitado, restringido, y lo que es limitado debe inevitablemente crear fragmentación cuando actúa. El pensamiento mismo es la causa de todas las divisiones, de todas las fragmentaciones». Krishnamurti, La mente que no mide, EDHASA, Barcelona, 1985, p. 115.

${ }^{23}$ Se pregunta la Dra. Thérèse Brosse: «¿Cómo podría inquietarnos el leer en el Shakta Vedanta que el Universo es Energía y que la Energía es conciencia [...] que la dualidad de «sujeto-objeto» es una ilusión? ¿O cuando un sabio hindú afirma, en virtud de su «experiencia interior» que nada de lo que vemos es real... que la vida es un sueño?». Conciencia-energía, Taurus, Madrid, 1981, pp. 23-24.

24 «Cuando el hombre sueña no sabe que está soñando. Sólo al despertar se da cuenta de su sueño. Y así, sólo en el momento del gran despertar se podrá saber que todo ha sido un gran sueño. Mas los estúpidos se tienen por despiertos, que todo lo saben. Ahora reyes, ahora pastores, iqué grandísima ignorancia! Ese Confucio y vos, los dos estáis soñando. Y cuando os digo que soñáis, también es sueño» (Zhuang zi II, VI). Para W. Shakespeare: «Estamos hechos de la misma materia que los sueños, y nuestra pequeña vida cierra su círculo con un sueño». La tempestad, Cátedra, Madrid, 1994, p. 355.

25 «En el transcurso de la formación hasta llegar a ser una persona normal, adecuada a la imagen particular de la cultura de lo que es normal, se ha manipulado selectivamente nuestra naturaleza básica. Se han moldeado significativamente nuestra percepción, nuestro pensamiento, nuestros sentimientos emocionales, nuestras convicciones e intuiciones y nuestra conducta. Nuestra conciencia ordinaria no es «natural», sino que es un producto adquirido [...] Para referirme a la naturaleza adquirida [...] lo sustituiré por [...] conciencia consensual». Ch. Tart, El despertar del self, Kairós, Barcelona, 1990, p. 34.

${ }^{26}$ «Nuestra concepción ordinaria del mundo como complejo de cosas que se extienden por el espacio y suceden unas tras otra en el tiempo no es más que un mapa convencional del universo; no es real. No es real porque esta imagen generada por el conocimiento simbólicocartográfico depende de la división del universo en cosas independientes vistas en el espacio/tiempo, por una parte, y el observador de dichas cosas por otra. Para que esto ocurra, el universo debe dividirse necesariamente en observador y observado [...] Por consiguiente, nuestras imágenes simbólicas convencionales y dualistas son sutiles falsificaciones de la misma realidad que pretenden representar.

Dicha división, sin embargo, más que falsa es ilusoria, y las filosofías, psicologías y ciencias que dependen de la misma no son por tanto erróneas sino absurdas». K. Wilber, El espectro de la conciencia, ed. cit., p. 99. 
to $^{27}$, parcial, «saturado de ignorancia refinada ${ }^{28}$, insustancial, impermanente $^{29}$, transitorio $^{30}$, doloroso $^{31}$, imprevisible, peligroso $^{32}$ e incluso hostil.

La afirmación de no-dualidad no ha sido ajena a la sabiduría occidental, aunque no ha recibido la atención filosófica que merece. En efecto, místicos tan renombrados como Jakob Boehme, William Blake y Meister Eckhart ${ }^{33}$, entre

27 «Vivimos en un mundo de conflictos y oposición porque es un mundo de demarcaciones y fronteras [...] la mayoría de nuestros problemas lo son de demarcaciones y de los opuestos que éstos crea [...] la forma en que de ordinario intentamos resolver estos problemas es tratar de extirpar uno de los opuestos [...] Lo que importa es que siempre tendemos a tratar la demarcación como si fuera real, y después manipulamos los opuestos así creados. Aparentemente, jamás cuestionamos la existencia de la demarcación como tal. Y como creemos que ésta es real, imaginamos tercamente que los opuestos son irreconciliables, algo que está para siempre separado y aparte [...] Dios y el diablo, la vida y la muerte, el bien y el mal, el amor y el odio, uno y los otros [...] Esta meta de separar los opuestos y después aferrarse a las mitades positivas o correr en pos de ellas, parece ser una característica distintiva de la civilización occidental progresista». K. Wilber, La conciencia sin fronteras, Kairós, Barcelona, 1985, pp. 36, 37 y 38.

28 «El saber no nos enriquece sino que nos aleja cada vez más del mundo místico, en el cual tuvimos una vez nuestra verdadera patria». C. G. Jung, Recuerdos, sueños y pensamientos, Seix Barral, Barcelona, 1986, p. 258.

29 «Y, tomar como permanente lo que es transitorio no es más que una ilusión de loco». Kalu Rimpoché, La práctica del budismo tibetano, Barath, Madrid, 1948, p. 20.

30 «La idea de que el mundo es un ensueño — que aparece reflejada también en el hinduismo y el budismo- proviene principalmente de su transitoriedad más que de especulaciones sobre el conocimiento y la verdad, la epistemología y la ontología, aunque estos conceptos se introducen después». A. Watts, El camino del Tao, Kairós, Barcelona, 1995, p. 132.

31 «Los principios fundamentales del budismo fueron resumidos por Buda en las tres partes de la negación: 1. Ninguno de los elementos tiene yo (sarvadharma anatmata); 2) Todas las cosas componentes son impermanentes (sarvasamskara antityata); 3) Todo es sufrimiento (sarvam duhkham), o, para decirlo en las palabras de Stcherbatsky, no hay sustancia, no hay duración, no hay bienaventuranza». J. Takakusu, «El budismo como filosofía de "asidad”», en Filosofía en Oriente, VV.AA., Fondo de Cultura Económica, México-Buenos Aires, 1965, p. 124; véase también M. ${ }^{a}$ T. Román, Un viaje al corazón del budismo, Alianza, Madrid, 2007, pp. 64-73.

32 «Nuestro estado de conciencia habitual no es algo natural o dado, sino una construcción sumamente compleja, un instrumento especializado para hacer frente a nuestro medio y a las gentes que en él se encuentran, una herramienta útil para afrontar determinadas situaciones pero que resulta inútil, e incluso peligrosa cuando tratamos de aplicarla a otras situaciones». Ch. Tart, «La aproximación sistémica de la conciencia», en R. Walsh y F. Vaughan (eds.), Trascender el ego, Kairós, Barcelona, 2003, p. 69.

33 «Aun en Eckhart y Fichte, observamos que la base de su filosofía está en el dualismo ser y no ser, vida y muerte, unidad y multiplicidad. En ocasiones, es cierto, parecen ir más allá de la antítesis; pero como su pensamiento da vuelta originalmente en torno al eje dualista, siempre retor- 
otros, han expresado de manera incuestionable su total convencimiento de que la experiencia no-dual es más real que nuestra habitual experiencia dualista. «Su mundo, afirma Nisargadatta, es personal, privado, incompatible e íntimamente suyo. Nadie puede entrar en él, ver como usted ve, oír como usted oye, sentir sus emociones y pensar sus pensamientos. En su mundo usted está verdaderamente solo, encerrado en un sueño siempre-cambiante que usted considera vida. Pero mi mundo es un mundo abierto, común a todos, accesible a todos. En mi mundo hay comunidad, comprensión, amor, calidad real; el individuo es lo total, y la totalidad es el individuo. Todos son uno y el Uno es todos» ${ }^{34}$. Aunque no de una forma tan clara y contundente como los anteriores, filósofos de la talla de Schelling, Spinoza, Hegel, Bergson, Shopenhauer, Whitehead, Nietzsche, Heidegger y Wittgenstein, también se han referido a la no-dualidad entre observador y observado ${ }^{35}$. «No hay un mundo objetivo fuera de nosotros, afirma Bede Griffiths, como opuesto al mundo subjetivo del interior. Hay una Realidad, que se manifiesta objetivamente fuera de nosotros y subjetivamente dentro, pero que está más allá de la distinción sujeto-objeto» ${ }^{36}$. Por su parte, Jung escribió: «La diferencia $[\ldots]$ entre los demás hombres y yo consiste en que mis "tabiques» son transparentes ${ }^{37}$.

Diversas Sabidurías Orientales, entre las que figuran el vedânta advaita hindú ${ }^{38}$, algunas corrientes del taoísmo filosófico y las escuelas mâdhyamaka y

nan a él después de haber hecho una excursión llamada mística por el campo de la identidad». D. T. Suzuki, «Una interpretación de la experiencia zen», en VV.AA., ob. cit., p. 192.

34 Sri Nisargadatta, Yo soy eso. Conversaciones con Sri Nisargadatta Maharaj, Sirio, Málaga, 2003, p. 42.

35 Véase D. Loy, ob. cit., p. 15.

36 B. Griffiths, ob. cit., p. 27.

37 C. G. Jung, ob. cit., p. 359.

38 «El Vedânta no es una "filosofía» en el sentido habitual de la palabra, sino sólo en el sentido que toma en la expresión "Philosophia Perennis», y a condición de que tengamos en mente la "filosofía» hermética o aquella "sabiduría» por la que fue consolado Boecio. Las filosofías modernas son sistemas cerrados, que utilizan el método dialéctico y dan por supuesto que los opuestos son mutuamente excluyentes [...] En la filosofía moderna, las cosas son o no son; en la filosofía eterna, depende de la perspectiva. La metafísica no es un sistema, sino una doctrina coherente; no se ocupa meramente de la experiencia condicionada y cuantitativa, sino de la posibilidad universal. Considera por tanto posibilidades que pueden no ser posibilidades de manifestación y también posibilidades que pueden manifestarse fuera del dominio formal, así como conjuntos de posibilidades que pueden realizarse en un mundo dado. La realidad última de la metafísica es una Identidad Suprema en la que se resuelve la oposición de todos los contrarios, incluso la oposición 
yogâchâra del budismo mahâyâna, como ya hemos señalado, han afirmado de forma clara y categórica la «irrealidad del mundo fenoménico» y la existencia de una forma no dual de experimentar el mundo. Para aquellas Sabidurías sólo existe una única Realidad, atemporal, infinita, no-dual, perfecta, que según diversas sabidurías orientales recibe los nombres de Mente, Talidad, Dharma-dhâtu, Vacuidad, Conciencia (en el budismo mahâyâna), Brahman, Âtman, (en el hinduismo); Tao (en el taoísmo), etc. Pero, según el hinduismo a través del proceso de mâyâ, del pensamiento dualista, introducimos dualidades o divisiones ilusorias "generando dos universos a partir de uno solo». Dichas segmentaciones no son reales, pero el ser humano actúa como si lo fueran y, presa de dicho engaño, inicia un proceso de fraccionamiento y de discriminaciones incorporadas a la realidad, que en apariencia origina fenómenos. «Aquel que está en el hombre y aquel que está en el sol son uno [...] Yo soy el alimento, yo soy el alimento, yo soy el alimento, yo soy el que come el alimento; yo soy el que come el alimento, yo soy el que come el alimento; yo soy el que da la gloria, yo soy el que da la gloria, yo soy el que da la gloria [...] yo como al que come el alimento" ${ }^{39}$. "No existe diversidad en ninguna parte. A esto se llega a través de la mente purificada. Pero el que sigue viendo diferencias aquí, va de muerte en muerte» ${ }^{40}$. Y en palabras de Shankara, máximo exponente del vedânta advaita: «En realidad, Yo soy el Brahman supremo que es eterno, puro, libre, único, beatitud sin partes, no dual, infinita Existencia y Conocimiento» ${ }^{41}$. Por su parte, Nisargadatta Maharaj afirma la posición tradicionalmente no-dual de la escuela vedânta advaita: «Confundir las apariencias con lo real es un pecado grave y la causa de todas las calamidades. Usted es la conciencia en-sí infinitamente creativa, todoabarcante y eterna. Todo lo demás es local y temporal» ${ }^{42}$. La caracterización no dual de la Realidad tam-

de ser y no ser; sus «mundos» $\mathrm{y}$ «dioses» son niveles de referencia y entidades simbólicas; no lugares ni individuos, sino estados de ser, susceptibles de realización en el interior de cada uno [...] La «filosofía» metafísica se llama "perenne» en razón de su eternidad, universalidad e inmutabilidad; es la «sabiduría increada, la misma ahora que ha sido siempre y siempre será», que decía Agustín». A. Coomaraswamy, El Vedanta y la tradición occidental, Siruela, Madrid, 2001, pp. 14-15. En otro de sus libros, Coomaraswamy declara: «La tradición hindú es una de las formas de la Philosophia Perennis y, como tal, encarna las verdades universales que ningún pueblo ni ninguna época podrían reivindicar como posesión exclusiva». Hinduismo y budismo, Paidós Orientalia, Barcelona, 1997, p. 20.

39 Taittirîya Upanishad 39, 3.10,4. En la edición de F. Tola, ob. cit., p. 276.

40 Katha Upanishad II, 11. En la edición de C. Martín, Upanisad con los comentarios advaita de Sankara, Trotta, Madrid, 2001, p. 98.

41 Shankara, La esencia del Vedânta, Kairós, Barcelona, 1997, pp. 66-67.

42 Nisargadatta Maharaj, ob. cit., p. 77. 
bién está presente en el taoísmo filosófico. En el Zhuang zi (VI,I) leemos: «(El Cielo y el hombre son uno), y no importa si el hombre gusta de ello o deja de gustar, que todo es uno». «Si alguien [...] conoce que la vida y la muerte, y el tener y el perder, son una y la misma cosa, a ése tendré por amigo» (VI,V). «Si no hay otro, no hay yo; si no hay yo, no hay nada que pueda manifestarse» (II,II). En el budismo mahâyâna está aún más desarrollada la «doctrina» de la no-dualidad: «Abandonad esos erróneos pensamientos que conducen a falsas distinciones. No hay ni «yo» ni «el otro». No hay ni «malos deseos», ni «cólera», ni «odio», ni «cariño», ni «triunfo», ni «fracaso». Con que sólo renunciéis al error del pensamiento intelectual o conceptual, vuestra naturaleza exhibirá su prístina pureza, pues sólo ésta es la manera de obtener la iluminación» ${ }^{43}$. Para Nâgârjuna: «la naturaleza propia de todas las cosas es semejante a una imagen reflejada; su esencia, pura, calma, es carente de dualidad, igual a la realidad absoluta ${ }^{44}$.

Podrían citarse, a este respecto, tantos pasajes de textos hindúes, budistas y chinos que bien podría afirmarse, sin temor a caer en la exageración, que las Sabidurías orientales no duales tienen por esencia la noción de advaita («no dualidad» $)^{45}$; y que la naturaleza no-dual de la realidad sólo se revela en la experiencia de no-dualidad a la que se da distintos nombres, a saber: «despertar», «iluminación», «liberación», «moksha», «nirvâna», «satori», «shînyatâ», etc.: «Mientras que la existencia empírica del ser humano está marcada por el sufrimiento y la esclavitud debido al efecto ilusorio de su ignorancia espiritual, la iluminación espiritual revela una realidad eterna, en la que no pueden darse dualidad o limitación alguna. Puesto que la distinción entre objeto y sujeto no tiene cabida en ella, interpretarla resulta obviamente difícil. Ha sido descrita en el Vedânta como el autoconocimiento, en base a su calidad de consciencia inmediata no objetiva. Ha sido descrita por el budismo como Vacuidad, en función de su ausencia de determinación. También ha sido descrita como revelación de la Divinidad, en la medida en que puede ser concebida como la única fuente de la que puede surgir la totalidad de sujetos y objetos. Lo cierto es que todas estas interpretaciones

43 J. Blofeld (ed.), Enseñanzas zen de Huang Po, Diana, México, 1976, p. 111.

44 F. Tola y C. Dragonetti, Budismo mahayana, Kier, Buenos Aires, 1980, p. 133.

45 «La intuición advaita no consiste en afirmar la Unidad, ni en negar la dualidad, sino precisamente, con una visión que trasciende el intelecto, en reconocer la ausencia de dualidad en el trasfondo de una realidad que en sí misma carece de dualidad; a saber, que no es numérica puesto que no tiene un dos. O sea que ni la unidad ni la dualidad corresponden a la estructura propia de la realidad». R. Panikkar, Espiritualidad hindú. Sanâtana dharma, Kairós, Barcelona, 2005, p. 205. 
son obras de la razón especulativa, por lo que no resultan adecuados para la experiencia no dual $»^{46}$.

El conocimiento no-dual está más allá de los condicionamientos propios de otras clases de conocimiento; concretamente, de su condicionamiento fundamental: la separación entre sujeto y objeto. Sin embargo, aun aceptando, denunciando, e incluso, demostrando la posibilidad de otras formas de experimentar, interpretar y relacionarse con «un mundo exterior» más sana, más gratificante y más profunda, la forma dual de conocer es la que se ha impuesto a cualquier otra: "Con la utilización de métodos y técnicas de meditación y concentración (en el seno del budismo theravâda, del zen japonés, del vajrayâna tibetano, del yoga hindú, etc.), idóneas para provocar transformaciones de la conciencia, los analistas promovieron el trabajo empírico de los estados no ordinarios de conciencia. Además, el estudio de los textos orientales ha puesto de relieve la existencia de mapas de la conciencia que los investigadores occidentales recién empiezan a vislumbrar y a enlazar con las concepciones y la información empírica de Occidente» ${ }^{47}$.

\section{EI mundo percibido como mâyâ}

Nuestro mundo es una fuente inagotable de opuestos: sujeto frente a objeto, organismo frente a medio, verdad frente a falsedad, realidad frente a apariencia, cuerpo frente mente, bondad frente a maldad, intelecto frente a instinto, espíritu frente a materia, ser frente a no ser, partícula frente a onda, triunfo frente a fracaso, vida frente a muerte, Absoluto frente a relativo, belleza frente a fealdad, reposo frente a movimiento, luz frente a oscuridad, etc. Para Alan Watts: «La filosofía especulativa, tal como la conocemos en Occidente es casi por completo un síntoma de la mente dividida, del hombre que trata de permanecer fuera de sí mismo y su experiencia a fin de verbalizarla y definirla. Es un círculo vicioso, como todo lo demás que intenta la mente dividida ${ }^{48}$.

46 C.G. Pande, «Dos dimensiones de la religión: reflexiones basadas en la experiencia espiritual y en las tradiciones filosóficas hindúes", en E. Deutsch (ed.), Cultura y modernidad, Kairós, Barcelona, 2001, p. 314.

${ }^{47}$ M. a T. Román, «Conciencia mística: más allá de la dualidad», en F. Rodríguez Bornaetxea (ed.), Psicología y conciencia, Kairós, Barcelona, 2007, p. 332.

48 A. Watts, La sabiduría de la inseguridad, Kairós, Barcelona, 1991, p. 114. 
Por su parte, Ken Wilber insiste en que sólo existe la Mente, Brahman, Tao, Shûnyatâ, la Cabeza Divina, Conciencia Cósmica, Dharmâkaya, pero a través del proceso de $m a \hat{y} \hat{a}^{49}$, del pensamiento dualista, insertamos dualidades o segmentaciones ficticias, "“creando dos mundos de uno solo", ese proceso dualista auténticamente creativo aunque ilusorio, no real sino «imaginario», una manifestación ficticia de lo absoluto con la apariencia de la totalidad de los fenómenos. Maya es el poder creativo de la cabeza divina, que se vierte o refleja en todas las cosas y de ese modo las crea, el poder de la subjetividad absoluta para adoptar una apariencia objetiva. En realidad, la cabeza divina permanece vacía, pero se presenta o manifiesta sólo como objetos. Este poder de apariencia/creación fenoménica es lo que se denomina maya» ${ }^{50}$. En palabras de Fritjof Schuon: «En el Absoluto no hay diferenciación, pues ésta pertenece por definición a la relatividad, a Mâyầ ${ }^{51}$. Por su parte, Joseph Campbell se refiere al concepto de mâyâ desde tres ópticas: "en primer lugar, el poder de un dios o demonio para crear espejismos, cambiar de forma y aparecer bajo máscaras engañosas; en segundo

49 «La palabra deriva de la raíz sánscrita matr-, «medir, formar, construir o trazar un plan», raíz de donde obtenemos palabras grecolatinas como metro, matriz, material y materia. El procedimiento fundamental de la medida es la división [...] Así la raíz sánscrita dva-, de donde derivamos la palabra «dividir», es también la raíz de la palabra latina duo (dos) y de la española «dual».

Decir, por tanto, que el mundo de los hechos y sucesos es maya equivale a decir que los hechos y sucesos son términos de medida más bien que realidades de la naturaleza. Sin embargo, debemos ampliar el concepto de medida de modo que incluya el poner límites de toda clase, tanto por la clasificación descriptiva como por el cribado selectivo. Así será fácil ver que los hechos y los sucesos son tan abstractos como las líneas de latitud o los pies y las pulgadas. Consideremos por un momento que es imposible aislar un solo hecho, separarlo totalmente. Los hechos se presentan de a pares por lo menos, pues un cuerpo solo es inconcebible aparte del espacio que ocupa. El acto de definir, de poner límites, de delinear, es siempre acto de división y, por ende, de dualidad, pues tan pronto como define un límite tiene dos lados [...] Una adecuada comprensión de la doctrina maya es uno de los requisitos más esenciales para estudiar el Hinduismo y el Budismo [...] El mundo no es una ilusión de la mente en el sentido de que, ante los ojos del hombre liberado (jivan$m u k t a$, no hay nada que ver salvo un vacío sin huella. El liberado ve el mundo que nosotros vemos; pero no lo amojona, mide y divide de la misma manera que nosotros. No lo considera como real o concretamente quebrado en sucesos y cosas separadas [...] tanto los hindúes como los budistas prefieren decir que la realidad es «no dual» [...] La doctrina de maya es una doctrina de relatividad. Consiste en decir que las cosas, los hechos y los sucesos son delineados no por la naturaleza sino por la descripción humana y que la manera como los describimos (o dividimos) es relativa a nuestros variables punto de vista». A. Watts, El camino del zen, EDHASA, Barcelona, 1971, pp. 60-62.

50 K. Wilber, El espectro de la conciencia, ed. cit., pp. 133-134.

51 F. Schoun, Tras las huellas de la religión perenne, José J. Olañeta, Barcelona, 1982, p. 22. 
lugar, «magia», la producción de ilusiones [...] y, por último, en el discurso filosófico, la ilusión impuesta sobre la realidad como resultado de la ignorancia» ${ }^{52}$. Según Huston Smith: «Maya es una advertencia, una llamada de atención para que no nos quedemos atrapados en el hechizo del mundo. De ahí la insistencia del Buda en la "atención plena" ${ }^{53}$. Por último, Heinrich Zimmer afirma lo siguiente: «Mâyâ denota el carácter insustancial y fenoménico del mundo que observamos y manejamos, así como de la mente misma y aun de los estratos y facultades conscientes y subconscientes de la personalidad ${ }^{54}$.

Los sabios-filósofos de la India empleaban el concepto de mâya para referirse a la condición ilusoria, inasible y evanescente del universo fenoménico. La escuela vedânta advaita, tal como la sistematizó Shankara, pone el énfasis en el concepto de $m \hat{a} y \hat{a}^{55}$. Heinrich Zimmer, autor de una de las mejores introducciones generales al pensamiento de la India, ha recogido este divertido cuento para ilustrar la doctrina de māya

«Se nos dice que un viejo guru estaba por concluir las lecciones secretas que había estado dando a un alumno adelantado acerca de la omnipresencia de la Persona Espiritual divina. Mientras el discípulo escuchaba, recogido y lleno de felicidad por aprender, el sabio y anciano maestro decía:

—Todo es Dios, el Infinito, puro y real, ilimitado y más allá de los pares de opuestos, libre de cualidades, diferenciales y distinciones limitadoras. Éste es el sentido último de todas las enseñanzas de nuestra santa sabiduría.

El alumno comprendió y dijo:

-Dios es la única realidad. A ese Uno Divino podemos encontrarlo en todo, sin padecer sufrimientos ni ningún otro defecto. Cada tú y yo es $\mathrm{Su}$ morada, toda forma es una figura obnubiladora en cuyo interior habita el único e inactivo Activador.

Estaba exaltado; una oleada sentimental lo traspasó y se sintió luminoso [...] Sublime, como la única nube en una completa soledad, caminaba por

52 J. Campbell, Las máscaras de Dios. Mitología oriental, Alianza, Madrid, 1991, p. 28.

53 H. Smith, La verdad olvidada. El factor común de todas las religiones, Kairós, Barcelona, 2001, pp. 120-121.

${ }^{54}$ H. Zimmer, Filosofias de la India, EUDEBA, Buenos Aires, 1979, p. 28.

55 Véase F. García Bazán, Neoplatonismo y Vedânta. La doctrina de la materia en Plotino y Shânkara, Depalma, Buenos Aires, 1982, pp. 171-203. 
el medio de la carretera, cuando un enorme elefante apareció en dirección opuesta. El cornaca, sentado sobre el cuello del animal, le gritó:

- Apártate! - Y los incontables cascabeles de la red que cubría a la enorme bestia dejaron oír una cascada de sonidos argentinos siguiendo el ritmo del suave e inaudible paso. El exaltado estudioso de la ciencia vedantina, aunque lleno de divinos sentimientos, oyó y vio al elefante que se aproximaba y se preguntó:

_ ¿Por qué habré de dejar paso a ese elefante? Yo soy Dios; el elefante es Dios. ¿Tendrá Dios miedo de Dios? - Y así, intrépidamente y con fe, continuó en medio de la carretera. Pero cuando Dios se acercó a Dios, el elefante arrolló su trompa en torno a la cintura del pensador y lo arrojó fuera del camino. El suelo era duro y el discípulo se lastimó un poco, pero su estupor era aún mayor. Cubierto de polvo, magullado y renqueando, con mente confusa, volvió al maestro y le contó su rara experiencia. El guru lo escuchó serenamente y cuando el cuento hubo terminado replicó sencillamente:

-En efecto, tú eres Dios, y también el elefante. Pero, ¿por qué no escuchaste la voz de Dios que desde el cornaca, que también es Dios, te pedía dejar paso? ${ }^{56}$.

Mâyâ se suele traducir por «ilusión», porque los filósofos del vedânta insistían en que sólo el Ser Absoluto, Brahman, es real; todo lo demás es ilusión, espejismos, sombras parpadeantes o sueños. Según la escuela vedânta advaita, cuando «mi», «yo», «lo mío», etc. están presentes, también se manifiesta mâyâ: «Mâyâ es toda experiencia que se constituye y procede de la distinción entre sujeto y objeto, de la distinción entre el sí mismo y lo otro.

Cuando transformamos lo impersonal en personal, es decir, cuando transformamos a Brahman en algo, o en alguien que se preocupa (de algo), ponemos en asociación a lo impersonal con mâyâ. Mâyâ es el estado óntico-noético en el que se superponen limitaciones (upâdhis) a la Realidad.

Todos los apegos, aversiones, miedos, sueños y semisueños pertenecen a mâyâ. Todos los recuerdos, cogniciones, perceptos y construcciones lógicas se fundamentan en mâyâ. Mâyâ existe cuando dejamos de realizar la unidad de lo Real.

${ }^{56}$ H. Zimmer, ob. cit., pp. 29-30. 
Mâyâ es sin principio (anâdi) porque el tiempo brota de ella, es impensable (acintya) porque todos los pensamientos están sujetos a ella, es indescriptible (anirvacanîya) porque todo lenguaje surge de ella. El nivel de ser que hemos calificado de Apariencia es por consiguiente mâyâs ${ }^{57}$.

El pensamiento budista lleva esta concepción del universo como ilusiones creadas e imaginadas (mâya), un paso más allá. Según el budismo, la realidad es «vacuidad» (shûnyatâ). En el Prajñâpâramitâ hridaya sûtra leemos: «La forma es vacuidad y vacuidad es realmente la forma. La vacuidad no es diferente de la forma, la forma no es diferente de la vacuidad. Lo que es forma eso es vacuidad, lo que es vacuidad eso es forma ${ }^{58}$.

\section{La «comunidad del lenguaje»}

La poderosa y eficaz "comunidad del lenguaje», ese vigoroso ejército de estructuras lingüísticas y modelos lógicos e interpretativos, se pone en marcha para mantener vivo, activo y cohesionado el mundo de la dualidad (mâyâ): «El lenguaje es para nosotros como el agua para el pez, un fenómeno de fondo tan permanente en nuestra experiencia que no somos conscientes del mismo. Es cierto que solemos ser conscientes de algunas funciones del lenguaje; podemos, por ejemplo, ser conscientes de la manipulación y elección de símbolos para transmitir un significado a los demás y la mayoría de nosotros somos por lo menos vagamente conscientes de las reglas gramaticales que rigen las oraciones que formulamos. Pero el lenguaje desempeña una función constante, de la que somos casi totalmente inconscientes: crea distinciones. Es decir, que el lenguaje, y su descendiente la intelección abstracta constituye la fuente principal de los dualismos humanos»"

Como la herramienta que empleamos para representar la naturaleza es en sí dualista, no dudamos en afirmar que así es la propia naturaleza: "Cada individuo se convierte en seguida en el beneficiario y la víctima de la tradición lingüística en la que ha nacido: el beneficiario en cuanto el lenguaje procura acce-

57 E. Deutsch, ob. cit., pp. 38-39.

58 E.B. Cowell (ed.), Buddhist Mahayana Texts, Dover Publications, Nueva York, 1969, p. 148.

59 K.Wilber, ob. cit., pp. 169-170. 
so a las acumuladas constancias de la experiencia ajena y la víctima en cuanto le confirma en la creencia de que ese reducido conocimiento es el único conocimiento y en cuanto deja hechizado su sentido de la realidad, en forma que cada cual se inclina demasiado a tomar sus conceptos por datos y sus palabras por cosas reales» ${ }^{60}$. Según Huxley: «Wordsworth escribe que «nuestro intelecto entremetido [esa parte de la mente que utiliza el lenguaje para despojar a la Realidad de su misterio] desfigura la bella forma de las cosas: asesinamos para disecar». No hace falta aclarar que no podemos progresar sin nuestro intelecto entremetido. El pensamiento conceptual verbalizado es indispensable. Pero incluso cuando los empleamos correctamente, los conceptos verbalizados desfiguran «la bella forma de las cosas. Y cuando, como sucede tan a menudo, los empleamos incorrectamente, desfiguran nuestra vida al racionalizar antiguas estupideces, al instigar asesinatos masivos, persecuciones, y la ejecución de todas las otras piruetas fantásticamente repulsivas que hacen llorar a los ángeles. La lúcida pasividad no verbal es un antídoto para la necia actividad verbal y un medio necesario para corregir la lúcida actividad verbal ${ }^{61}$. Y más adelante, el célebre escritor inglés afirma: «Los artistas, los visionarios y los místicos se niegan a dejarse esclavizar por los hábitos culturalmente condicionados de la sensación, el pensamiento y la acción que su sociedad considera correctos y naturales. Cuando esto les parece deseable, se abstienen deliberadamente de proyectar sobre la realidad los esquemas semánticos sacrosantos con los que están tan copiosamente pertrechadas todas las mentes humanas. Saben tanto como el que más que la cultura y el lenguaje en los cuales hinca sus raíces cualquier cultura dada son absolutamente necesarios, y que, sin ellos, el individuo no sería humano. Pero también saben, más vivamente que el resto de la humanidad, que para ser cabalmente humano, el individuo debe aprender a librarse de su condicionamiento, debe estar en condiciones de perforar boquetes en la valla de símbolos verbalizados que lo aprisiona ${ }^{62}$.

Las Sabidurías orientales no duales, aun cuando emplean el lenguaje, lo hacen siempre con cautela, siendo conscientes de que las palabras son meros mapas y no el territorio. En este sentido, Alfred Korzybski, uno de los más destacados investigadores de la semántica moderna, afirma: «a map is not the terri-

${ }^{60}$ A. Huxley, Las puertas de la percepción cielo e infierno, EDHASA, Barcelona, 1979, p. 23.

61 A. Huxley, Moksha, EDHASA, Barcelona, 1982, p. 353.

62 Ibíd., pp. 355-356. 
tory it represents» ${ }^{63}$. En sus Memorias, Alan Watts señala: «Apenas se reconoce la vasta diferencia que hay entre la descripción del mundo y el mundo tal como lo sentimos; apenas se reconoce que lo que describimos, en el universo físico, como cosas separadas pertenece al orden de las hipótesis y las opiniones, es decir, que no se trata de hechos sino de interpretaciones» ${ }^{64}$. Como afirman R. Sohl y S. Carr en Games Zen Masters Play: "Confundir la naturaleza indivisible de la realidad con las diferenciaciones y casilleros conceptuales del lenguaje constituye la ignorancia básica de la que el Zen intenta liberarnos. Las últimas respuestas al problema de la existencia no se encuentran en conceptos intelectuales ni en filosofías, por muy sofisticados que éstos sean, sino más bien en un nivel de experiencia directa no conceptual que nunca puede limitarse a la naturaleza dualística del lenguaje» ${ }^{65}$. En palabras de D.T. Suzuki: «El hombre ha creado muchos conceptos valiosos que le han ayudado a manejar la realidad. Pero ha terminado confundiendo los conceptos con la realidad, el pensamiento con la experiencia y el sistema con la vida. Al olvidar que los conceptos son una creación suya deja de estar en contacto con la realidad. El zen, por su parte, es plenamente conciente de este hecho y todos sus mondos están dirigidos a desenmascarar la falsa conceptualización. Es por ello que el zen parece ser tan irracional y enturbia la imagen de sentido común que tenemos del mundo» ${ }^{66}$. Radhakrishnan declara: «El Veda es visto u oído, no hecho por sus autores humanos. Es descubrimiento espiritual, no creación. La vía de la sabiduría no es la de la actividad intelectual. Desde los comienzos, la India creyó en la superioridad de la intuición, o método de percepción directa de lo supersensible, sobre el razonamiento intelectual» ${ }^{67}$.

El lenguaje es para el budismo mahâyâna la fórmula menos apropiada para aprehender y expresar la verdad. En efecto, en el Lankâvatâra-sûtra encontramos las siguientes afirmaciones: «El lenguaje, Mahâmati, no es la última verdad [...] Porque la verdad última es aquello de lo que el sabio disfruta; por medio del lenguaje uno puede penetrar en la verdad, pero las propias palabras no son la ver-

63 A. Korzybski, Science and Sanity, The International Non Aristotelian Library Publishing Company, Lakeville, 1980, p. 58.

${ }_{64}$ A. Watts, Memorias, Kairós, Barcelona, 1980, p. 11.

${ }_{65}$ M. Talbot, Misticismo y física moderna, Kairós, Barcelona, 1986, pp. 184-185.

${ }^{66}$ D.T. Suzuki, Vivir el zen, Kairós, Barcelona, 1994, pp. 35-36.

67 S. Radhakrishnan, «Hinduismo», en G.T. Garrat (ed.), El legado de la India, Pegaso, Madrid, 1950 , p. 375.

ENDOXA: Series Filosóficas, n. ${ }^{\circ}$ 25, 2010, pp. 103-127. UNED, Madrid 
dad. Ésa es la auto-realización interna vivenciada por el sabio a través de su suprema sabiduría y no pertenece al dominio de las palabras, discriminación o inteligencia ${ }^{68}$.

Sabios-filósofos como Lao zi conocen muy bien los límites de las palabras: «El que sabe no habla, el que habla no sabe» (LVI). Y el Zhuang zi (II, III) dice: «La palabra no es como el soplar del viento. El que habla expresa razones, mas estas razones no son algo permanente. ¿Habla realmente? ¿O es que acaso no habla? Imagina que sus palabras son diferentes del piar de un pajarillo. ¿Se distinguen? ¿O acaso no se distinguen?».

Para expresar los contenidos de no-dualidad desarrollados por las Sabidurías orientales, el lenguaje tiene que adoptar unas formas especiales que asuman las limitaciones propias de lo privado, de lo íntimo, de lo incomunicable de la experiencia de no-dualidad. En palabras de Heinrich Zimmer: "Hay en la filosofía occidental una larga e imponente serie de distinguidos maestros, como Pitágoras, Empédocles y Platón, Plotino y los neoplatónicos, los místicos medievales, Spinoza y Hegel, que se ocupan en problemas situados más allá de la esfera del sentido común y que sólo pueden expresarse en fórmulas difíciles y por medio de paradojas. La filosofía india procede de la misma manera. Los pensadores orientales son tan conscientes como los occidentales de que los medios ofrecidos por la mente y las facultades racionales son inadecuados para aprehender y expresar la verdad. El pensamiento está limitado por el lenguaje. El pensar es como una silenciosa conversación interior. Lo que no puede formularse con las palabras y símbolos corrientes de una tradición dada no existe para el pensar usual. Por consiguiente requiere cierto esfuerzo creador de parte de un espíritu intrépido y fervoroso que irrumpa a través de las palabras para llegar hasta lo tácito, es decir, para llegar a divisarlo. Y luego hace falta otro esfuerzo para traerlo al campo lingüístico y acuñar un nuevo término. Desconocida, innominada, inexistente al parecer, pero en realidad existiendo, la verdad tiene que ser conquistada, descubierta y traducida al lenguaje: donde, inevitablemente, acto continuo volverá a ser mal comprendida ${ }^{69}$.

\footnotetext{
68 D.T. Suzuki, Studies in the Lankavatara Sutra, SMC Publishing, Taipei, 1991, p. 244.

${ }^{69}$ H. Zimmer, ob. cit., p. 31.
} 


\section{Conclusiones}

Para que pueda evolucionar una filosofía más holística ${ }^{70}$, más integral, más completa $^{71}$, algo más próximo a la Sabiduría, hay que incorporar líneas de pensamiento, doctrinas y concepciones como la que acabamos de exponer y que están fuera del marco de la filosofía occidental ${ }^{72}$. Ha llegado el momento de renunciar a esa inveterada costumbre de imponer una camisa de fuerza conceptual a todo lo «ajeno» y dejar que cada uno rellene los «espacios vacíos» como le convenga. En la era de la globalización ya no quedan albergues para los que pretenden conservar a costa de lo que sea sus obsoletos y encorsetados discursos y reducir la Sabiduría a un determinado mapa conceptual —el suyoignorando o subestimando al mismo tiempo las articulaciones doctrinales y los logros procedentes de otros universos cognitivo-emocionales-operativos. Para Lin Yutang: «De los esparcidos fragmentos del conocimiento moderno debe

70 «Dondequiera que miremos, decía el filósofo Jan Smuts, no vemos más que totalidades. Totalidades jerárquicas que forman parte de totalidades mayores, integradas, a su vez, en totalidades superiores. Campos dentro de campos que, a su vez, están incluidos dentro de otros campos, extendidos a través de todo el cosmos, entrelazando entre sí todas y cada una de las cosas [...] El cosmos no es perezoso sino energéticamente dinámico (e incluso creativo) y tiende a producir totalidades cada vez más elevadas, inclusivas y organizadas. Este proceso cósmico global que se despliega a lo largo del tiempo no es otro que la evolución. Smuts denominaba holismo a ese impulso encaminado hacia unidades superiores». K. Wilber, Los tres ojos del conocimiento. La búsqueda de un nuevo paradigma, Kairós, Barcelona, 1991, p. 109.

${ }^{71}$ «Fuera del mundo occidental, la filosofía y la teología apenas pueden separarse, incluso en Occidente fueron compañeras a lo largo de la Edad Media e, incluso, hasta más tarde. Clemente describió al cristianismo como la confluencia de dos ríos. Atenas y Jerusalén, y Tomás de Aquino forjó la síntesis medieval incorporando la metafísica de Aristóteles a los cimientos de la teología cristiana. En la Edad Media, la filosofía era la sirvienta de la teología y (con Hume como disidente solitario) Dios continuó siendo el cerebro de los grandes sistemas metafísicos de la modernidad hasta Hegel. La de Hegel fue la última filosofía teísta importante; sin embargo, aunque el idealismo alemán y el romanticismo ralentizó el avance de la visión científica del mundo, pronto en el siglo XX el positivismo lógico quitó del medio a los dos. La filosofía del lenguaje frenó al positivismo en el tercer cuarto de dicho siglo, pero éste terminó con las premisas materialistas nuevamente en su sitio. Recuerdo al lector la afirmación de John Searle citada anteriormente según la cual los profesionales de la filosofía aceptan alguna versión del materialismo porque creen que es la única filosofía consistente con la ciencia contemporánea». H. Smith, La importancia de la religión en la era de la increencia, Kairós, Barcelona, 2002, pp. 113-114.

72 En 1939, en la Universidad de Hawai, tuvo lugar una reunión de filósofos norteamericanos y asiáticos con el objetivo de estudiar la posibilidad de una filosofía universal mediante una síntesis de Oriente y Occidente.

ENDOXA: Series Filosóficas, n. ${ }^{\circ}$ 25, 2010, pp. 103-127. UNED, Madrid 
construirse un nuevo mundo, y Oriente y Occidente deben construirlo conjuntamente» ${ }^{73}$.

Nuestra mente endurecida y maleada por la utilización de un sistema cognitivo-emocional-operativo dual, opuesto, consensuado, jerarquizado, muy deficiente, excluyente y exclusivo y que potencia la frustración, el desencanto, el enfrentamiento, la crueldad, la guerra, el terrorismo y la desigualdad social, debería hacer el esfuerzo de recuperar lo más «auténtico» que anida en el seno de sí misma, o sea, el amor, la sabiduría y la compasión, y fomentar una filosofía que ayude a resolver algunos de los graves problemas que nos afligen: «La filosofía occidental se está avellanando. No son pocos los que piensan que, en el momento actual, no ofrece gran cosa a nuestra generación perdida, hambrienta de claridad, de renovación y de verdad. Los graves problemas que afectan a la humanidad y al planeta exigen reformas estructurales que pasan por una transformación profunda del ser humano - y no por una filosofía de salón- para que éste pueda conjurar el desequilibrio que ha llevado a hablar de una crisis de la civilización ${ }^{74}$.

Hoy más que nunca tenemos que dirigir nuestros esfuerzos e inteligencia hacia el cultivo de la imaginación, la introspección y la meditación, tan necesario en la presente "Edad de Hierro» (Kali yuga). Tal vez así nuestro ojo interno podría recuperar paisajes «íntimos» de cuya existencia apenas queda memoria y horizontes preñados de posibilidades cuyo conocimiento puede conducirnos hacia espacios mentales más enriquecedores, abiertos, integradores, comprensivos y compasivos.

\section{Bibliografía}

ARnau, J. [ed.] (2004). Fundamentos de la vía media, Madrid: Siruela.

- (2005). La palabra frente al vacío. Filosofía de Nâgârjuna, México: Fondo de Cultura Económica.

Blofeld, J. [ed.] (1976). Enseñanzas zen de Huang Po, México: Diana.

${ }_{73}$ Lin Yutang, Sabiduría china, Biblioteca Nueva, Buenos Aire, 1959, p. 17.

${ }^{74}$ M. ${ }^{a}$ T. Román, «El corazón de Oriente», en Hesperia Culturas del Mediterráneo, Año II, vol. III (2006), p. 275. 
BORGES, J. L. (1980). Prosa completa, vol. 2, Barcelona: Bruguera.

Brosse, T. (1981). Conciencia-energía, Madrid: Taurus.

CAmpbell, J. (1991). Las máscaras de Dios. Mitología oriental, Madrid: Alianza.

CoOmaraswamy, A. (2001). El Vedanta y la tradición occidental, Madrid: Siruela.

- (1997). Hinduismo y budismo, Barcelona: Paidós Orientalia.

Cowell, E. B., [ed.] (1969). Buddhist Mahayana Texts, New York: Dover Publications.

Deussen, P. (1966). The philosophy of the Upanishads, New York: Dover Publications,

Deutsch, E. (1999). Vedânta Advaita. Una reconstrucción filosófica, Madrid: Etnos.

- [ed.] (2001). Cultura y modernidad, Barcelona: Kairós, Barcelona.

Fromm, E. y SuzUKI, D. T. (1975). Budismo zen y psicoanálisis, Madrid: Fondo de Cultura Económica.

García BAZÁN, F. (1982). Neoplatonismo y Vedânta. La doctrina de la materia en Plotino y Shânkara, Buenos Aires: Desalma..

GarRat, G. T., [ed.] (1950). El legado de la India, Madrid: Pegaso.

GRIFFITHS, B. (1985). El matrimonio de Oriente y Occidente, Madrid: Ediciones Paulinas.

GuÉNON, R. (1987). Los estados múltiples del ser, Barcelona: Obelisco.

Hume, R. E. [ed.] (1998). The thirteen principal Upanishads, New Delhi: Oxford University Press.

HuXLEY, A. (1979). Las puertas de la percepción cielo e infierno, Barcelona: EDHASA.

- (1982). Moksha, Barcelona: EDHASA, Barcelona.

James, W. (1986). Las variedades de la experiencia religiosa, Barcelona: Península.

JunG, C. G. (1986). Recuerdos, sueños y pensamientos, Barcelona: Seix Barral.

KALU RIMPOCHÉ (1948). La práctica del budismo tibetano, Madrid: Barath.

KorZYBSKI, A. (1980). Science and Sanity, The International Non Aristotelian Library Lakeville: Publishing Company.

KRISHNAMURTI (1985). La mente que no mide, Barcelona: EDHASA.

LiN YUTANG (1959). Sabiduría china, Buenos Aires: Biblioteca Nueva. 
Lovejoy, A. O. (1983). La Gran Cadena del Ser. Historia de una idea, Barcelona: Icaria. Loy, D. (2000). No dualidad, Barcelona: Kairós.

MARTín, C. [ed.] (2001). Upanisad con los comentarios advaita de Sankara, Madrid: Trotta.

Merton, T. (1999). El zen y los pájaros del deseo, Barcelona: Kairós.

NisargadatTA (2003). Yo soy eso. Conversaciones con Sri Nisargadatta Maharaj, Málaga: Sirio.

PanikKar, R. (2005). Espiritualidad hindú. Sanâtana dharma, Barcelona: Kairós. Preciado, I. [ed.] (1996). Zhuang zi "Maestro Chuang Tsé», Barcelona: Kairós.

RADHAKRISHNAN, S. [ed.] (1953). The principal Upanisads, London: Allen \& Unwin.

- (1943). The philosophy of the Upanishads, Paris: Librairie d'Amérique et d'Orient.

Ramana Maharshi (1986). Enseñanzas espirituales, Barcelona: Kairós.

Rodríguez Bornaetxea, F. [ed.] (2007). Psicología y conciencia, Barcelona: Kairós.

Román, M.a T. (2007). Un viaje al corazón del budismo, Madrid: Alianza.

— (2006). «El corazón de Oriente», en Hesperia Culturas del Mediterráneo, Año II, vol. III.

SATPREM (1983). Sri Aurobindo o la aventura de la consciencia, Barcelona: Obelisco.

SCHRÖDINGER, E. (1988). Mi concepción del mundo, Barcelona: Tusquets.

Schoun, F. (1982). Tras las huellas de la religión perenne, Barcelona: José J. Olañeta.

SHAKESPEARE, W. (1994). La tempestad, Madrid: Cátedra.

SHANKARA (1997). La esencia del Vedânta, Barcelona: Kairós..

Smith, H. (2002). La importancia de la religión en la era de la increencia, Barcelona: Kairós.

- (2001). La verdad olvidada. El factor común de todas las religiones, Barcelona: Kairós.

SuzuKI, D. T. (1981). Ensayos sobre budismo zen, Primera Serie, Buenos Aires: Kier.

- (1991). Studies in the Lankavatara Sutra, Taipei: SMC Publishing.

- (1994). Vivir el zen, Barcelona: Kairós.

TALBOT, M. (1986). Misticismo y fisica moderna, Barcelona: Kairós.

TART, Ch. (1990). El despertar del self, Barcelona: Kairós. 
TolA, F. (1980). Budismo mahayana, Buenos Aires: Kier.

— [ed.] (1973). Doctrinas secretas de la India Upanishads, Barcelona: Barral.

- (1977). Bhagavad-gîtâ. El canto del Señor, Caracas: Monte Ávila Editores.

VV.AA. (1965). Filosofía en Oriente, México-Buenos Aires: Fondo de Cultura Económica,

WaLSH, R., y Vaughan, F. [eds.] (2003). Trascender el ego, Barcelona: Kairós.

WATTS, A. (1971). El camino del zen, Barcelona: EDHASA.

- (1980). Memorias, Barcelona: Kairós, Barcelona.

- (1981). Nueve meditaciones, Barcelona: Kairós.

- (1991). La sabiduría de la inseguridad, Barcelona: Kairós.

- (1995). El camino del Tao, Barcelona: Kairós.

WILBER, K. (1985). La conciencia sin fronteras, Barcelona: Kairós.

- (1990). El espectro de la conciencia, Barcelona: Kairós, Barcelona.

- (1991). Los tres ojos del conocimiento. La búsqueda de un nuevo paradigma, Barcelona: Kairós.

- (1995). Después del edén, Barcelona: Kairós.

- (1998). El ojo del espíritu, Una visión integral para un mundo que está enloqueciendo poco a poco, Barcelona: Kairós.

Zimmer, H. (1979). Filosofias de la India, Buenos Aires: EUDEBA.

Recibido: $14 / 01 / 2010$

Aceptado: 14/06/2010 
